\title{
NOT1(CDC39), NOT2(CDC36), NOT3, and NOT4 encode a global-negative regulator of transcription that differentially affects TATA-element utilization
}

\author{
Martine A. Collart ${ }^{1}$ and Kevin Struhl ${ }^{2}$ \\ Departments of Biological Chemistry and Molecular Pharmacology, Harvard Medical School, \\ Boston, Massachusetts 02115 USA
}

The yeast HIS3 $T_{R}$ and $T_{C}$ TATA elements support basal transcription, but only $T_{R}$ can respond to transcriptional activators. Four genes, NOT1(CDC39), NOT2(CDC36), NOT3, NOT4, act as general negative regulators and preferentially affect $T_{C}$-dependent transcription. Allele-specific suppression, a two-hybrid interaction, and biochemical cofractionation suggest that NOT1 and NOT2 are nuclear proteins associated in a discrete, 500-kD complex. NOT4 interacts with NOT1 and NOT3 in the two-hybrid assay, and overexpression of NOT 3 or NOT4 suppresses not 1 and not 2 mutations. Repression by the NOT proteins is not attributable to inhibition of transcriptional activators, does not involve the CYC8/TUP1 negative regulatory complex, and is distinct from repression by nucleosomes or by the SPT4,5,6 proteins that affect chromatin structure. We propose that the NOT proteins inhibit the basic RNA polymerase II transcription machinery, possibly by affecting TFIID function.

[Key Words: NOT genes; negative regulators; transcription; TATA element; repression complex]

Received August 18, 1993; revised version accepted January 18, 1994.

It has become increasingly evident that RNA polymerase II transcription involves intermediary proteins that are distinct from the basic initiation factors and from specific DNA-binding activators and repressors. By definition, such intermediary proteins do not interact efficiently with DNA, but rather become associated with promoters through protein-protein interactions. Intermediary transcription factors can function by mediating interactions between activators/repressors and the basic transcription machinery, and/or by maintaining or alleviating a repressive chromatin structure. Depending on the mechanism involved, an intermediary protein might affect transcription of a small number of related genes or it might globally affect the transcription of many genes.

In the yeast Saccharomyces cerevisiae, a number of intermediary proteins that act as global positive and negative regulators of transcription have been identified by mutations (for review, see Struhl 1993). On the basis of phenotypic similarities and extragenic suppressor analyses, some of these regulators have been grouped functionally and proposed to form multiprotein complexes.

\footnotetext{
${ }^{1}$ Present address: Department of Biochimie Medicale, Centre Medical Universitaire, 1211 Geneve 4, Switzerland.

${ }^{2}$ Corresponding author.
}

One potential complex includes the SNF2/SWI2, SNF5, SNF6, SWI1, and SWI3 proteins, which are important for transcriptional enhancement by a variety of DNA-bound activators (Laurent et al. 1991; Hirschhorn et al. 1992; Laurent and Carlson 1992; Peterson and Herskowitz 1992; Yoshinaga et al. 1992). The SPT4, SPT5, and SPT6 proteins carry out a negative regulatory function, probably as a complex (Swanson and Winston 1992). Phenotypic similarities between spt4,5,6 and histone mutations suggest that these SPT proteins may affect transcription by altering chromatin structure. The CYC8/ TUP1 complex (Williams et al. 1991), which is critical for repression of several transcriptional regulatory pathways, has been proposed to function by associating with specific DNA-binding proteins (Keleher et al. 1992; D. Tzamarias and K. Struhl, in prep). These putative multiprotein complexes clearly have distinct roles in transcription, but their mechanisms of action are not known.

Previously, we characterized CDC39 as an essential nuclear protein that negatively regulates transcription of many genes and differentially affects the functionally distinct TATA elements in the HIS3 promoter region (Collart and Struhl 1993). The HIS3 TATA elements $T_{C}$ and $T_{R}$ support basal transcription that depends on the TATA-binding protein (TBP), but only $T_{R}$ can respond to 
transcriptional activators such as GCN4 and GAL4 (Struhl 1986; Mahadevan and Struhl 1990; Cormack and Struhl 1992). $\mathrm{T}_{\mathrm{R}}$ contains the sequence TATAAA and behaves as a typical TATA element /Chen and Struhl 1988; Ponticelli and Struhl 1990; Wobbe and Struhl 1990), whereas $T_{C}$ lacks a conventional TATA sequence and is unable to support transcription in vitro (Mahadevan and Struhl 1990; Ponticelli and Struhl 1990). Unlike activator proteins that function through $\mathrm{T}_{\mathrm{R}}, C D C 39$ affects $T_{C}$-dependent transcription preferentially (Collart and Struhl 1993). Thus, $T_{C}$-dependent transcription is controlled by a global negative regulatory pathway involving CDC39. For these and other reasons, we now refer to CDC39 as NOT1 (negative on TATA).

In this paper we identify three additional genes, NOT2(CDC36), NOT3, and NOT4, that behave as general negative regulators and preferentially affect $T_{C}$-dependent transcription. We present genetic and biochemical evidence for a protein complex containing NOT1 and NOT2 and for functional interactions involving NOT3 and NOT4. Finally, we show that transcriptional inhibition by the NOT proteins is mechanistically distinct from that mediated by other global negative regulators such as the CYC8/TUP1 complex, histones, and SPT6. Thus, the NOT proteins define a novel mechanism of transcriptional repression that affects TATA-element utilization. Because the NOT proteins affect transcription from $T_{C}$ preferentially, the element that does not respond to activator proteins, we suggest that NOTmediated repression involves an interaction with a component of the basic transcription machinery.

\section{Results}

Identification of four NOT genes that negatively regulate HIS3 expression

Previously, we described a genetic selection for strains that increase HIS3 transcription by gcn4-C163, a derivative with a partially defective activation domain (Collart and Struhl 1993). The selection is based on the fact that the degree of GCN4 function is correlated with cell growth in medium containing aminotriazole (AT), a competitive inhibitor of the HIS3 gene product (Hope and Struhl 1986). Using this selection, we obtained 13 recessive mutations, all of which allow growth $\leqslant 40 \mathrm{~mm}$ $\mathrm{AT}$, unlike the parental strain that grows poorly at $5 \mathrm{~mm}$ and not at all in $10 \mathrm{~mm} \mathrm{AT}$.

Genetic analysis reveals that the 13 mutations fall into four complementation groups. As we have reported (Collart and Struhl 1993), one group is defined by a single temperature-sensitive mutation in CDC39, a gene implicated originally in cell-cycle control and the pheromone response (Reed 1980; Shuster and Byers 1989; de Barros Lopes et al. 1990). Our previous results argue strongly that $C D C 39$ is a transcriptional regulatory protein and not involved directly in cell-cycle control /Collart and Struhl 1993); for this reason and others to become apparent, we now refer to this gene as NOT1 (negative on TATA). NOT2 is defined by four mutations, three of which cause slow growth at $30^{\circ} \mathrm{C}$ and prevent growth at $37^{\circ} \mathrm{C}$; not2-4 grows normally at both temperatures. NOT3 is defined by seven mutations that do not cause detectable growth phenotypes on rich medium. NOT4 is defined by a single mutation that confers a slow growth phenotype at all temperatures. Growth phenotypes, when observed, always cosegregate with the AT-resistance phenotype in tetrads.

\section{NOT genes preferentially affect $T_{C^{-}}$ dependent transcription}

In the HIS 3 promoter region, $\mathrm{T}_{\mathrm{C}}$ is responsible for transcription from the +1 site, whereas $T_{R}$-dependent transcription is initiated almost exclusively from the +13 site (Struhl 1986; Chen and Struhl 1988; Mahadevan and Struhl 1990; Ponticelli and Struhl 1990|. Basal HIS3 transcription is initiated equally from +1 and +13 and involves both $T_{C}$ and $T_{R}$. Activator proteins, such as GCN4 and GAL4 function only with $T_{R}$ and stimulate +13 transcription. In contrast, loss of NOT1 function causes a novel phenotype in which basal transcription from the +1 site is increased preferentially /Collart and Struhl 1993). Increased transcription occurs rapidly with loss of NOT1 function, suggesting that NOT1 acts directly on the HIS3 promoter region. Mutational analysis indicates that NOT1 does not affect the inherent properties of the +1 and +13 initiator elements, but rather affects $\mathrm{T}_{\mathrm{C}}$-dependent transcription preferentially $\mid \mathrm{Col}$ lart and Struhl 1993).

We analyzed basal HIS3 transcription (i.e., GCN4 was deleted) in not mutant backgrounds at both $30^{\circ} \mathrm{C}$ and $38^{\circ} \mathrm{C}$ (Fig. 1A). For all alleles tested, a preferential increase in the HIS $3+1$ transcript is observed, but only at $38^{\circ} \mathrm{C}$ for the temperature-sensitive strains. As observed previously with the not1-2 strain /Collart and Struhl 1993), increased +1 transcription is observed within 30 min after shifting not1-1 and not2-1 strains to the restrictive temperature (data not shown). The levels of the +1 transcript differ among the mutant strains, with not $2-4$ and not3-2 strains showing the most dramatic increase. Thus, all four NOT genes regulate HIS3 expression negatively and affect $\mathrm{T}_{\mathrm{C}}$-dependent transcription preferentially.

The different levels of basal HIS3 transcription conferred by the various not mutations are surprising in light of the similar AT-resistance phenotypes, which are measured under conditions of transcriptional activation by gcn 4-C163. Therefore, we analyzed HIS3 transcription activated by gen4-C163 in wild-type and not mutant strains (Fig. 1B). As expected, strains containing gcn $4-\mathrm{Cl} 63$ show more +13 transcript than corresponding $g c n 4$ deletion strains (e.g., cf. the $+1 /+13$ ratio in lanes 1 and 10). Surprisingly, but in agreement with the AT-resistance phenotypes, the amount of HIS3 transcription activated by gen4-C163 is similar in all mutant strains. Thus, in the not $2-4$ and not $3-2$ strains, the level of +1 transcription in the presence of gen4-C163 is actually lower than the basal, non-GCN4-activated level (cf. lanes 4 and 5 with lanes 13 and 14). This observation 
A

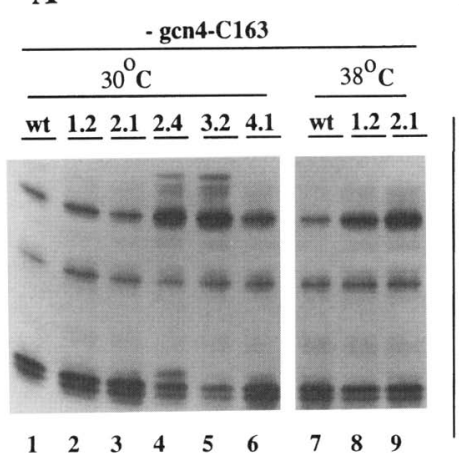

B

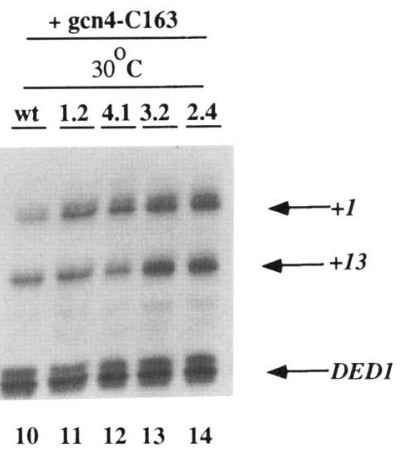

C

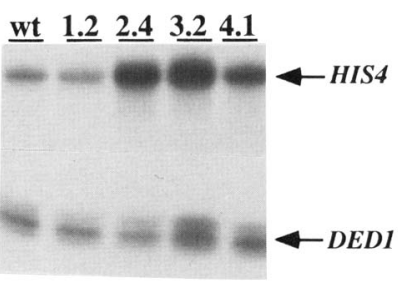

D

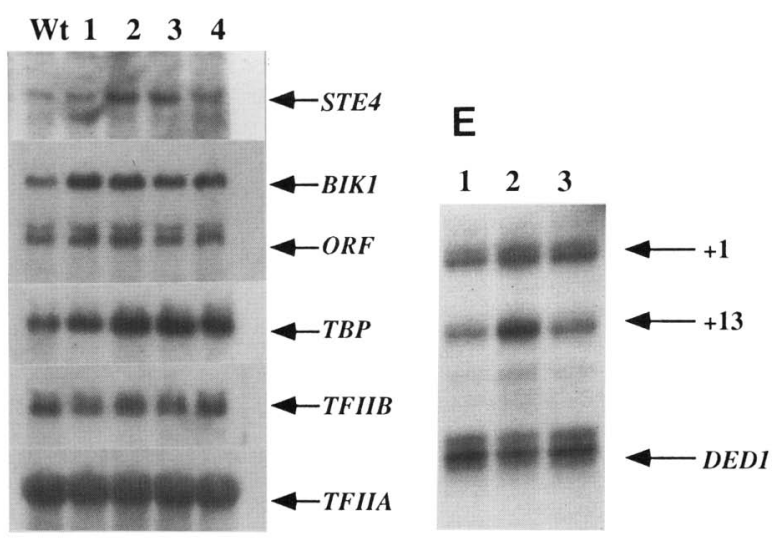

Figure 1. Transcriptional analysis. (A) gcn4 deletion strains containing the indicated not alleles were grown at the permissive $\left(30^{\circ} \mathrm{C}\right)$ or restrictive $\left(38^{\circ} \mathrm{C}\right)$ temperatures and analyzed for HIS3 $(+1$ and +13 transcripts) and DED1 RNAs by S1 treatment of RNA-DNA duplexes. $(B)$ Same as $A$ except that strains express gcn4-C163. (C) Same as A except that DED1 and HIS4 RNAs are analyzed. $(D)$ gcn4 deletion strains containing not1-2, not2-4, not3-2, and not4-1 were grown at $30^{\circ} \mathrm{C}$ and analyzed for STE4, $B I K 1, O R F, T B P, T F I I B$, and TFIIA RNAs by Northern blotting. $(E)$ $g c n 4$ deletion strains containing multicopy plasmids that express no protein (lane 1), TBP (lane 2), or TFIIB (lane 3) were grown at $30^{\circ} \mathrm{C}$ and analyzed as described in $A$. TBP RNA levels in lane 2 are $\sim 20$-fold higher than in lane 1 (data not shown).

suggests that in some cases, increased $T_{C}$-dependent transcription with loss of NOT function can compete with activation by GCN4 derivatives.

\section{The NOT proteins negatively regulate the same} spectrum of functionally diverse genes

Previous results indicate that NOT1 negatively regulates transcription of several unrelated genes; not1(cdc39)-2 confers increased basal transcription of HIS4 and TBP (encodes the TBP) at the restrictive temperature (Collart and Struhl 1993), and not1(cdc39)-1 confers increased $\alpha$-factor-dependent transcription of STE4 (de Barros Lopes et al. 1990), a gene involved in the pheromone response. As shown in Figure 1, C and D, basal (i.e., not activated by GCN4 or $\alpha$-factor) transcription of HIS4, TBP, STE4, and BIK1 lencodes a gene involved in nuclear fusion) is increased in not2, not3, and not 4 mutant strains grown at $30^{\circ} \mathrm{C}$. In contrast, RNA levels for $D E D 1$, the gene adjacent to BIK1 (ORF; Fig. 1D), and the genes encoding TFIIB and the small subunit of TFIIA are not increased in not mutant strains. We also analyzed transcription of these genes in the not1-2 strain grown at $30^{\circ} \mathrm{C}$, a condition of partial NOT1 function /Collart and Struhl 1993). Consistent with earlier results (Collart and Struhl 1993), basal HIS4 and TBP transcription is affected minimally. Basal transcription of STE4 is only slightly increased in this circumstance, whereas BIK1 transcription is increased to the same extent as observed in the other not mutant strains. Taken together, these results indicate that the four NOT proteins negatively regulate a diverse set of genes.

The fact that the genes encoding TFIIB and the small subunit of TFIIA are unaffected in not mutant strains indicates that NOT-mediated repression is not attributable to altered levels of TFIIB or TFIIA. Although not mutant strains show increased levels of TBP RNA, this increase is unlikely to be responsible for the not phenotype because overexpression of TBP does not significantly affect the level or initiation pattern of HIS3 transcription (Fig. 1E) or AT resistance.

\section{NOT2 is identical to CDC36}

NOT2 was cloned by complementation of the temperature-sensitive and AT-resistant phenotypes conferred by the not2-1 mutation, and the gene was mapped to a $3-\mathrm{kb}$ fragment (Sc3867; Fig. 2A). Genomic integration and genetic mapping indicate that an adjacent 2-kb DNA fragment (Sc3868) is tightly linked to the not2-1 mutation. Hybridization of the NOT2 gene to a collection of $\lambda$ bacteriophages covering most of the yeast genome /Olson et al. 1986) indicates that it maps close to the $C D C 36$ locus (L. Riles, pers. comm.). Like NOT1(CDC39), CDC36 was originally identified by temperature-sensitive mutations that cause cell-cycle arrest in $\mathrm{G}_{1}$ and constitutively ac- 
$\mathbf{A}$

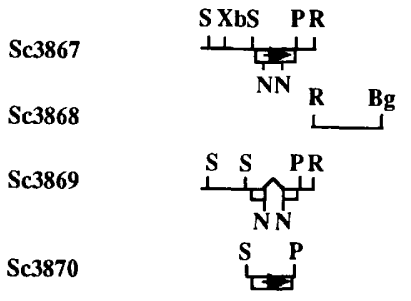

B

Sc3876

Sc3871

Sc3872

Sc3873

Sc3874

Sc3875

Sc3877

C

Sc3878

Sc3879

Sc3880

Sc3881

Sc3882

Sc3883 $37^{\circ} \mathrm{CAT}^{\mathrm{s}}$

$++$

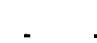

-

$++$

$\overline{\mathbf{1 k b}}$
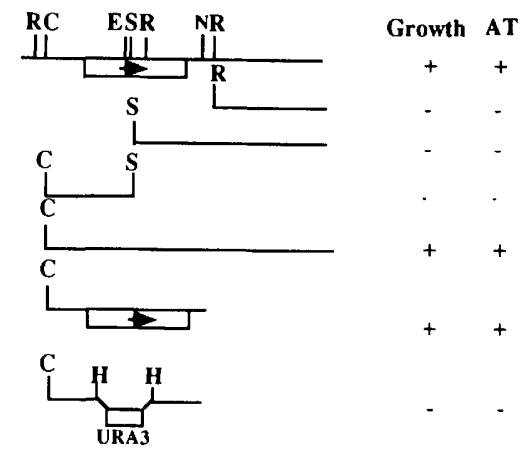

Growth AT

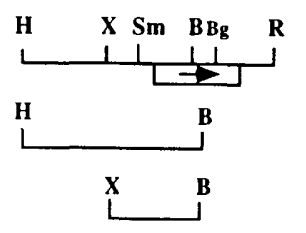

$++$
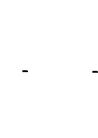

$+$

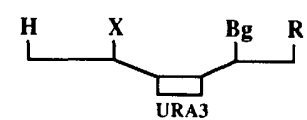

Figure 2. The NOT2, NOT3, and NOT4 loci. The structures and phenotypes (determined by complementation) of the indicated DNA fragments are shown. The location and orientation of each protein-coding sequence is indicated by the open box and arrow. Restriction sites are abbreviated as follows: (B) BamHI; (Bg) BglII; (C) ClaI; (E) EagI; (H) HindIII; (N) NdeI; (P) PstI; (R) EcoRI; (S) SacI; (Sm) SmaI; (Xb) XbaI; (X) XhoI.

tivate the pheromone response pathway (Reed 1980; Shuster and Byers 1989; de Barros Lopes et al. 1990). Restriction mapping and DNA sequencing confirms that Sc3867 contains CDC36. Moreover, a 500-bp internal deletion of CDC36-coding sequences (Sc3869) abolishes NOT2 activity, whereas a $1-\mathrm{kb}$ DNA fragment encompassing a minimal CDC36 locus (Sc3870) complements both phenotypes. Hence, NOT2 is identical to CDC36.

Although NOT2(CDC36) has been defined by temperature-sensitive mutations, it is not essential for vegetative growth; cells carrying a chromosomal deletion grow

very slowly at $30^{\circ} \mathrm{C}$ and not at all at $37^{\circ} \mathrm{C}$ on rich medium (S. Reed, pers. comm.). Three of our not2 alleles have the same phenotype as a null allele, whereas not2-4 grows normally on rich medium at all temperatures tested. Surprisingly, not $2-4$ confers the strongest $T_{C}$-dependent transcriptional effect, indicating that temperature sensitivity and transcriptional phenotypes are not strictly correlated. None of our not2 mutations are the result of severe alterations in the gene, as determined by genomic hybridization, and the 0.9-kb NOT2 RNA is expressed at equivalent levels in parental and not $2 \mathrm{mu}-$ tant strains (not shown). Interestingly, a high-copy plasmid containing NOT2 weakly suppresses the temperature-sensitive phenotype of not1-1 (Table 1).

\section{NOT3 is a high-copy suppressor of not 1 and not2} mutations

To clone NOT3, we took advantage of the observation (see below) that not3 mutations exacerbate the growth phenotypes of not2 temperature-sensitive mutations such that the double mutants grow very poorly at $25^{\circ} \mathrm{C}$ and $30^{\circ} \mathrm{C}$. We obtained one plasmid containing $\sim 15 \mathrm{~kb}$ of yeast DNA (Sc3876) that complements the slow-growth phenotype at $30^{\circ} \mathrm{C}$ but not the temperature-sensitive phenotype of a not2-1 not3-5 strain. Sc3876 contains NOT3 because it directs genomic integration to a site tightly linked to the not $3-1$ locus. By testing restriction fragments phenotypially, we located a SacI site that may be within the complementing gene (Fig. 2B). Partial DNA sequencing reveals that the region around the $\mathrm{SacI}$ site is identical to a sequence reported to be that of CDC39 (Ferguson et al. 1986) but clearly different from the correct sequence of NOT1(CDC39) (Collart and Struhl 1993). To prove that NOT3 was equivalent to this previously identified gene, we cloned a minimal DNA fragment encompassing the 835-residue open reading frame $(S c 3875)$ and showed that it complements both the slow-growth phenotypes of the not 2 not 3 double mutants and the AT-resistance phenotypes of the not $3 \mathrm{mu}-$ tants. NOT3 maps to the left arm of chromosome 9 as

Table 1. High-copy suppression

\begin{tabular}{lcccc}
\hline & \multicolumn{4}{c}{ Overexpressed NOT proteins } \\
\cline { 2 - 5 } not allele & NOT1 & NOT2 & NOT3 & NOT4 \\
\hline not1-1 & ++ & \pm & ++ & ++ \\
not1-2 & ++ & - & - & + \\
not2-1 & - & ++ & ++ & + \\
not2-2 & N.T. & ++ & N.T. & N.T. \\
not2-3 & - & ++ & ++ & N.T. \\
not4-1 & - & - & - & ++ \\
\hline
\end{tabular}

Growth at $37^{\circ} \mathrm{C}$ for strains containing the indicated not alleles and high-copy plasmids containing the indicated NOT genes. $1++\mid$ Wild-type growth; $|+|$ slower than wild-type; $( \pm)$ barely detectable; $(-)$ none. not 3 mutant strains grow normally at this temperature and hence were not examined (N.T.) Not tested. 
determined by hybridization to the collection of $\lambda$ bacteriophages.

Because NOT3 was originally identified in an attempt to clone NOT1 by complementation of the not1(cdc39)-1 allele (Ferguson et al. 1986), it seemed likely that NOT3 would act as a high-copy suppressor of not1 mutations. A multicopy plasmid containing NOT3 suppresses the temperature-sensitive growth phenotype of the not1-1 strain (Table 1), a finding supported by others (S. Reed, pers. comm.). However, overexpression of NOT3 does not suppress any of the phenotypes caused by a not1-2 strain. NOT3 overexpression also suppresses the temperature-sensitive phenotype of two different not2 mutations, but it has no effect on the slow-growth phenotype conferred by not4-1 (Table 1 ).

None of the not 3 mutations are the result of severe alterations in the gene, as determined by genomic hybridization, and the $2.8-\mathrm{kb}$ RNA is expressed at equivalent levels in the parental and not 3 mutant strains. We constructed a null allele of NOT3 (Sc3877) and found it to grow normally at all temperatures tested on rich medium. This strain has the same AT-resistance phenotype as the originally isolated not 3 mutant strains, and it shows the same preferential increase in $\mathrm{T}_{\mathrm{C}}$-dependent transcription (data not shown).

NOT4 is identical to SSF1 and is a high-copy suppressor of not 1 and not 2 mutations

NOT4 was cloned by complementation of the slow growth phenotype associated with the not $4-1$ mutation, and the gene was mapped to a $3.7-\mathrm{kb}$ fragment $(\mathrm{Sc} 3882$; Fig. 2C). Restriction mapping and partial DNA sequencing revealed that NOT4 is identical to $S S F 1$, a gene identified by mutations that suppress the mating defect in a ste 4 strain (K. Irie and K. Matsumoto, pers. comm.). The defining phenotype of ssf 1 mutations presumably reflects constitutive activation of the pheromone response pathway and, hence, is reminiscent of phenotypes conferred by the original $c d c 39$ (not1) and $c d c 36$ (not2) mutations. A null allele of NOT4 (Sc3883) confers the same growth and AT-resistance phenotypes as the not $4-1 \mathrm{mu}-$ tation, and it causes the same preferential increase in
$\mathrm{T}_{\mathrm{C}}$-dependent transcription (data not shown). As determined by hybridization to the collection of $\lambda$ bacteriophages, NOT4 lies centromeric to the ribosomal DNA locus on the right arm of chromosome 12 . In confirmation of a result obtained by $\mathrm{K}$. Irie and $\mathrm{K}$. Matsumoto (pers. comm.), a multicopy plasmid containing NOT4 suppresses the temperature-sensitive phenotypes of not1 and not 2 mutations (Table 1). Growth of the resulting strains at $37^{\circ} \mathrm{C}$ is slower than that of the parental strain, indicating that NOT4 overexpression does not compensate fully for loss of NOT1 or NOT2 function.

not2-4 is an allele-specific suppressor of not 1-2

To test for genetic interactions among the not mutations, we constructed all double mutant strains involving not 1-2 and not2-1 by standard genetic crosses. All of the double mutants are viable and, with one clear exception, grow similarly on $40 \mathrm{~mm}$ AT. In general, the double mutants grow slightly more slowly in rich medium than the corresponding single mutants. However, unlike strains containing individual mutations, all not2-1 not 3 double mutant strains grow very poorly at $25^{\circ} \mathrm{C}$ and $30^{\circ} \mathrm{C}$.

The exceptional double mutant, not1-2 not2-4, behaves similarly to the parental (NOT1 NOT2) strain on AT. Moreover, this double mutant strain grows well at $37^{\circ} \mathrm{C}$, although the not $1-2$ single mutant is temperature sensitive for growth. This allele-specific suppression is also observed at the transcriptional level (Fig. 3). In a typical double mutant, such as not1-2 not2-1, the basal level of the +1 transcript is slightly higher than that observed in the single mutants (cf. lanes 8 and 9 with 11). However, in the not1-2 not2-4 double mutant, the basal HIS3 levels are similar to those in the parental strain and much lower than in the not $2-4$ strain at $30^{\circ} \mathrm{C}$ (cf. lanes 1 , 4 , and 61 ; at $38^{\circ} \mathrm{C}$, the level of the +1 transcript is slightly higher than in the parental strain (lanes 7,12 ) but much lower than in the not2-4 mutant (lane 10). These observations indicate that not 2-4 and not 1-2 are mutual suppressor mutations that largely restore a wild-type phenotype, and they strongly suggest a direct interaction between NOT1 and NOT2.

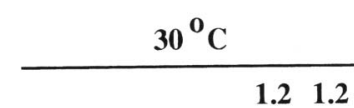

WT $1.2 \quad 2.12 .4 \quad 2.12 .4$

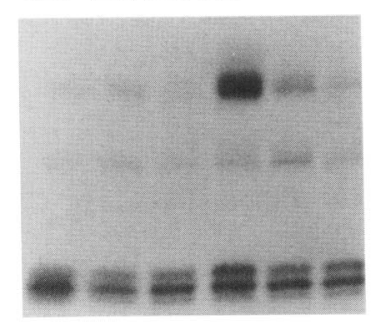

$\begin{array}{llllll}1 & 2 & 3 & 4 & 5 & 6\end{array}$

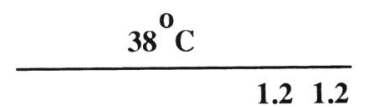

WT 1.22 .12 .42 .12 .4

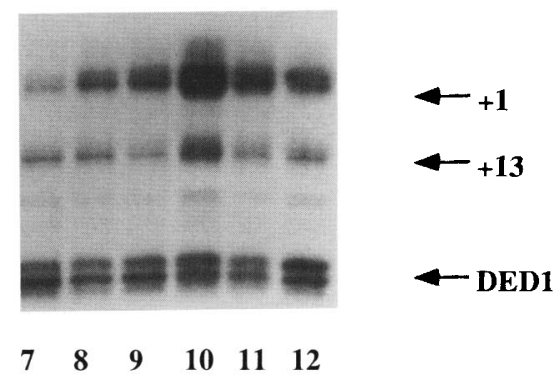

Figure 3. Allele-specific suppression. gcn 4 deletion strains containing the indicated not alleles were grown at the temperatures indicated and analyzed for HIS3 $1+1$ and +13 transcripts) and DED1 RNAs. The specific activity of the $D E D 1$ probe relative to the $H I S 3$ probe was twofold higher at $30^{\circ} \mathrm{C}$ (left) as compared with $38^{\circ} \mathrm{C}$ (right). 


\section{Two-hybrid interactions}

To provide independent evidence for interactions between NOT proteins, we used the two-hybrid assay (Fields and Song 1989) as modified by Zervos et al. (1993). NOT proteins were expressed as nuclearly localized, fusion proteins with either the LexA DNA-binding domain or the $\mathrm{B} 42$ acidic activation region; the fusion proteins confer NOT function as assayed by complementation. These proteins were analyzed, singly or in combination, for their ability to activate transcription of $L E U 2$ or $1 a c Z$ reporter genes containing LexA operators upstream of a TATA element (Table 2). Two-hybrid interactions are clearly detected between NOT1 and NOT2 (9-fold increase in $\beta$-galactosidase activity), NOT1 and NOT4 (20fold increase), and NOT3 and NOT4 (25-fold increase). These interactions are specific; other combinations of B42-hybrid proteins and LexA-NOT1 or LexA-NOT3 showed no increase in $\beta$-galactosidase activity. However, the combination of LexA-NOT3 and B42-NOT1 leads to a Leu ${ }^{+}$phenotype (Fig. 4), suggesting the possibility of a weak two-hybrid interaction between NOT3 and NOT1. LexA-NOT2 activates transcription on its own and, hence, is unsuitable for the two-hybrid assay. These results indicate that NOT1-NOT2, NOT1-NOT4, NOT3-NOT4, and perhaps NOT3-NOT1 are associated physically.

\section{NOT1 and NOT2 are nuclear proteins that are associated in a large complex}

The two-hybrid experiments establish that NOT1 and NOT2 can interact when both proteins are localized nuclearly. However, although NOT1 is a nuclear protein (Collart and Struhl 1993), the localization of NOT2 is unknown. Therefore, we analyzed total, nuclear, and cytoplasmic protein extracts by Western blotting with antibodies raised against NOT2 (kind gift from S. Reed, Scripps Institute, La Jolla, CA). As shown in Figure 5, NOT2 is detected as a protein with an apparent molecular mass of $22 \mathrm{kD}$, consistent with its expected size. The protein is detected in total and nuclear extracts but not in cytoplasmic extracts or in total extracts of strains deleted for NOT2 (kind gift from S. Reed). Thus, NOT1 and NOT2 are nuclear proteins and, hence, potentially able to interact in normal cells.

To provide biochemical evidence for a complex con-

Table 2. Two-hybrid assays

\begin{tabular}{|c|c|c|c|c|c|}
\hline \multirow[b]{2}{*}{$\begin{array}{l}\text { LexA hybrid } \\
\text { proteins }\end{array}$} & \multicolumn{5}{|c|}{ B42 activation domain hybrid proteins } \\
\hline & B42 & $\begin{array}{l}\text { B42- } \\
\text { NOT1 }\end{array}$ & $\begin{array}{l}\text { B42- } \\
\text { NOT2 }\end{array}$ & $\begin{array}{l}\text { B42- } \\
\text { NOT3 }\end{array}$ & $\begin{array}{l}\text { B42- } \\
\text { NOT4 }\end{array}$ \\
\hline LexA-NOT1 & 38 & 34 & 330 & 41 & 780 \\
\hline LexA-NOT2 & 870 & 1060 & 630 & N.T. & N.T. \\
\hline LexA-NOT3 & 21 & 15 & 17 & 19 & 550 \\
\hline
\end{tabular}

$\beta$-Galactosidase activities (Miller units/mg protein) of EGY42 derivatives expressing the indicated proteins. (N.T.) Not tested.

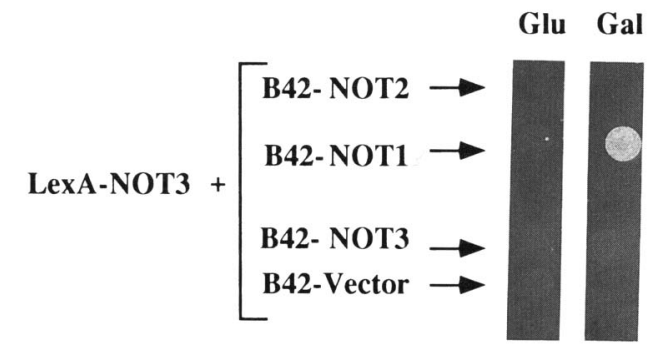

Figure 4. Two-hybrid interactions. EGY42 strains expressing LexA-NOT3 and the indicated B42 activation domain derivatives were plated on either $2 \%$ glucose (Glu) or $2 \%$ galactose (Gal) minimal medium lacking leucine and selective for plasmid maintenance. Colony growth requires activation of the LEU2 gene that is driven by a promoter containing six LexA operators upstream of the CYC1 TATA element.

taining NOT1 and NOT2, we fractionated proteins from cells expressing NOT2 and epitope-tagged NOT1 on a Superose 6 gel filtration column. Western blots reveal that NOT1 and NOT2 are not detected as monomeric species but, instead, cofractionate at a position corresponding to a molecular mass of $500 \mathrm{kD}$ (Fig. 6). Several observations indicate that this $500-\mathrm{kD}$ species represents a discrete multiprotein complex and is not attributable to nonspecific aggregation. First, the sharpness of the NOT1 and NOT2 protein peaks are similar to those of purified proteins run through the column as molecular mass markers. Second, the column was run in moderately high ionic strength $(0.35 \mathrm{M})$ and in the presence of detergent $(0.1 \%$ Tween $)$, conditions that do not favor aggregation. Third, NOT1 and NOT2 are separated easily from the vast majority of proteins in the extract that fractionate as species of lower molecular mass. Fourth, the sharpness of the peaks and the fact that the extracts contain $<1 \%$ of total cellular DNA make it highly unlikely that NOT1 and NOT2 cofractionate as a $500-\mathrm{kD}$ species as a result of their association with DNA. Thus, NOT1 and NOT2 are components of a large, multiprotein complex.

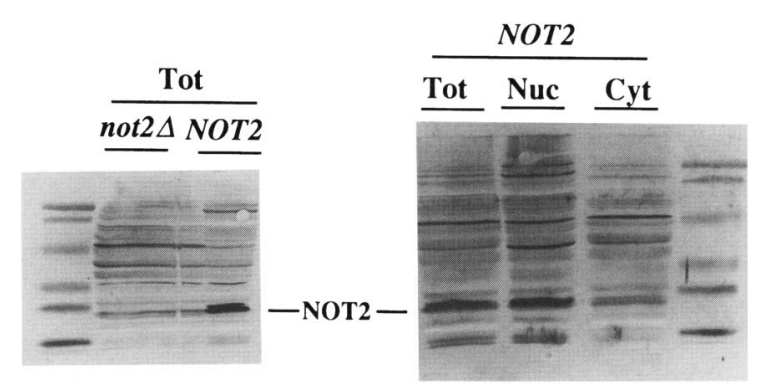

Figure 5. Subcellular localization of NOT2. Protein from total (Tot), nuclear (Nuc), and cytoplasmic (Cyt) extracts prepared from NOT2 (MY340) or not2::TRP1 (MY94) strains analyzed by Western blotting using specific antibodies to the NOT2 protein. The position of the $22-\mathrm{kD}$ NOT2 protein is indicated. 

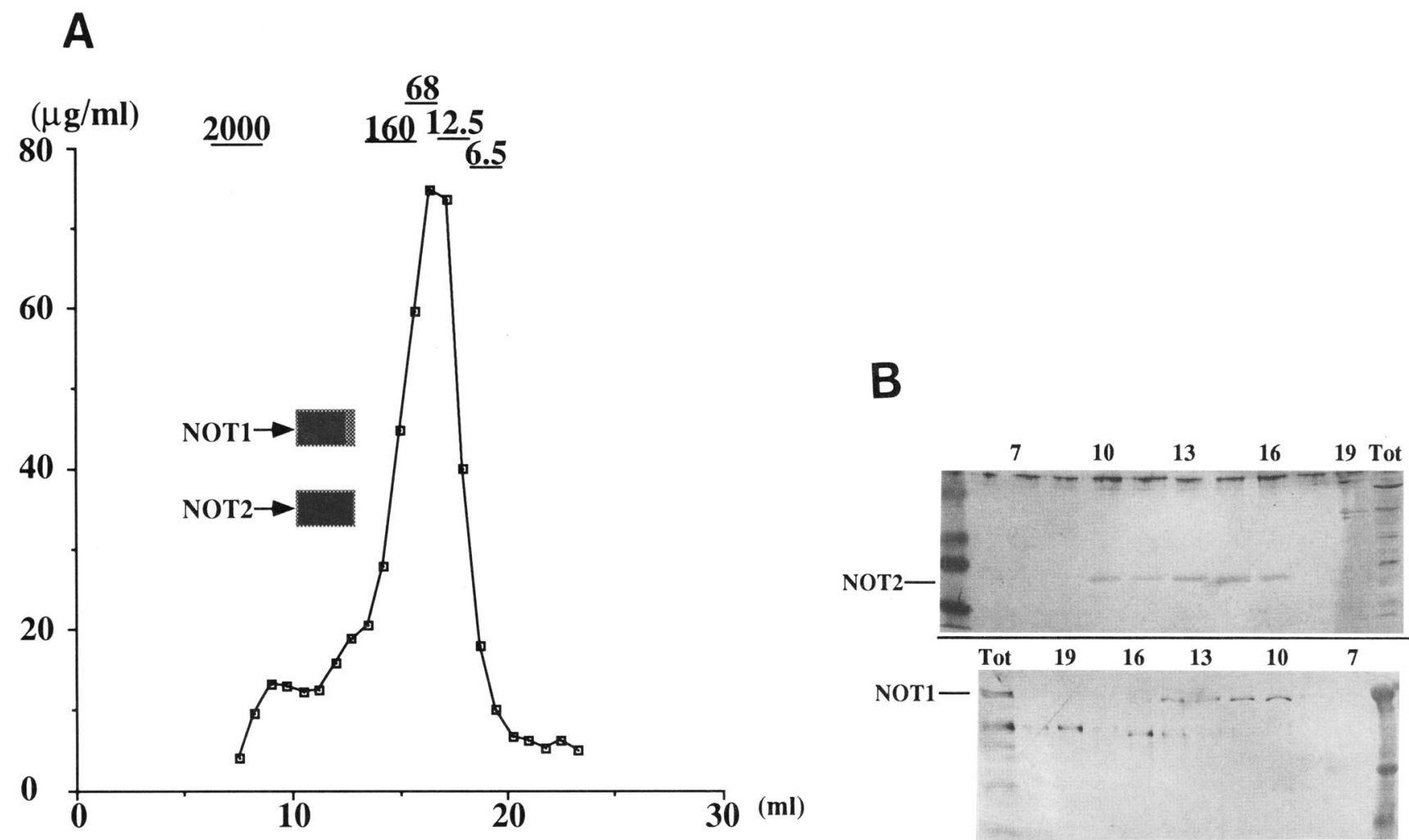

Figure 6. NOT1 and NOT2 are associated in a complex. Proteins from KY340 cells, which express NOT2 and a HA1-tagged NOT1 were separated on a Superose 6 column by fast protein liquid chromatography. Fractions (defined by ml eluted from the column) were assayed for protein content by the Bradford assay $(A)$ and for HA1-NOT1 and NOT2 by Western blotting $(B)$. Indicated on the graph are the fractions containing the molecular mass (in $\mathrm{kD}$ ) markers and the HA1-NOT1 and NOT2 (boxes; darker shading indicates stronger signal in Western blot). The positions corresponding to HAl-NOT1 and NOT2 on the Western blot are indicated; additional bands detected in HAl probing are cross-reactive species that do not depend on expression of HAl-NOT1 (Collart and Struhl 1993).

Negative regulation by the NOT proteins is distinct from repression by the Cyc8/Tup1 complex

The CYC8/TUP1 protein complex represses transcription of many genes regulated by cell type, glucose, and oxygen (Williams et al. 1991; Keleher et al. 1992). To examine the relationship between the CYC8/TUP1 complex and the NOT proteins, we analyzed basal HIS3 transcription in strains deleted for CYC8 or for TUP1. The levels of the +1 and +13 transcripts in cyc 8 or tup 1 mutant strains are indistinguishable from those in the wild-type strain (Fig. 7), indicating that negative regulation of HIS3 transcription by the NOT proteins is not mediated by the CYC8/TUPl complex.

CYC8 (Keleher et al. 1992), TUP1 (D. Tzamarias and K. Struhl, in prep), and SIN3 (Wang and Stillman 1993) can repress transcription when bound upstream of the intact CYC1 promoter by the heterologous LexA DNAbinding domain. To test whether the NOT proteins could repress transcription in this manner, we introduced LexA-NOT1, LexA-NOT2, and control proteins into strains containing $C Y C 1$ promoters that did or did not have upstream LexA operators (Table 3). LexANOT1 does not affect expression of either reporter gene, whereas LexA-NOT2 slightly increases transcription from the promoter containing the LexA operators. As expected, expression from the promoter containing LexA operators is increased by the transcriptional activator LexA-MyoD, whereas it is repressed by LexA-CYC8. Thus, unlike CYC8, TUP1, and SIN3, neither NOT1 nor NOT2 can repress transcription when brought to DNA

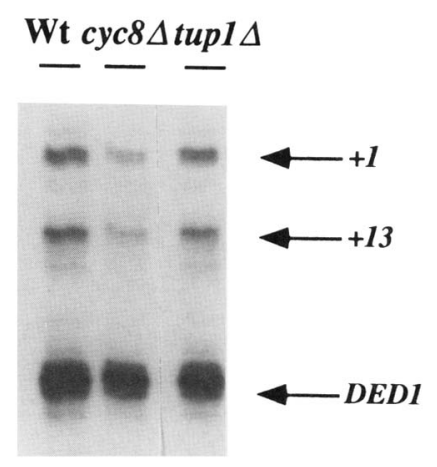

Figure 7. CYC8 and TUP1 are not required for NOT-mediated repression. gcn4-deleted strains containing cyc8::LEU2 (MY96) or tup 1::LEU2 (MY97) were analyzed for HIS3 (+1 and +13 transcripts) and DED1 RNAs. 
by a heterologous DNA-binding domain. In fact, NOT2 increases transcription in this artificial situation, in contrast to its effect on many native yeast genes.

NOT function is distinct from general chromatinbased repression

Because nucleosomes repress transcription globally, we considered the possibility that the NOT proteins are involved in maintaining normal chromatin structure. Previously, we argued against such a role (Collart and Struhl 1993) on the basis of the observation that loss of nucleosomes, obtained by repressing histone $\mathrm{H} 4$ expression, leads to an induction of $T_{R}$-dependent transcription (Durrin et al. 1992), an effect in contrast to that observed with loss of NOT function. However, as nucleosome loss severely disrupts chromatin structure, we examined basal HIS3 transcription in two other situations involving less dramatic alterations.

First, we examined the effect of two temperature-sensitive mutations in SPT6, a gene encoding a nonhistone protein implicated in maintaining normal chromatin structure (Swanson and Winston 1992), at permissive and restrictive temperatures (Fig. 8). Loss of SPT6 function at the restrictive temperature leads to increased transcription from the +13 site but does not affect transcription from the +1 site. Conversely, not mutations do not have an $\mathrm{Spt}^{-}$phenotype (not shown). Thus, negative regulation by the NOT proteins is mechanistically distinct from that mediated by SPT 6 and the putative SPT 4,5,6 complex.

Second, we analyzed basal HIS3 transcription in a strain containing a derivative of histone $\mathrm{H} 4$ that lacks the amino-terminal tail and affects transcriptional activation and silencing (Kayne et al. 1988; Durrin et al. 1991). In the presence (Fig. 8B) or absence (not shown) of GCN4, this amino-terminally deleted $\mathrm{H} 4$ protein leads to a severe loss of the +13 transcript but does not affect the level of +1 transcription. Thus, alterations in chromatin structure affect $T_{R}$ transcription preferentially, whereas NOT-mediated repression affects $T_{C}$-dependent transcription preferentially. These results suggest that the NOT proteins are not simply involved in maintaining the general repressive chromatin structure.

Table 3. Transcriptional repression by LexA hybrid proteins

\begin{tabular}{lcc}
\hline & \multicolumn{2}{c}{ Promoter (strain) } \\
\cline { 2 - 3 } LexA hybrid proteins & $\begin{array}{c}\text { CYC1 } \\
\text { (MY276) }\end{array}$ & $\begin{array}{c}\text { lexAop-CYC1 } \\
\text { (MY277) }\end{array}$ \\
\hline LexA-NOT1 & 182 & 172 \\
LexA-NOT2 & 248 & 428 \\
LexA-MyoD & 110 & 1573 \\
LexA-CYC8 & 174 & 7 \\
\hline
\end{tabular}

$\beta$-Galactosidase activities (Miller units/mg protein) of strains containing the indicated LexA hybrid proteins and CYC1-lacZ promoters.

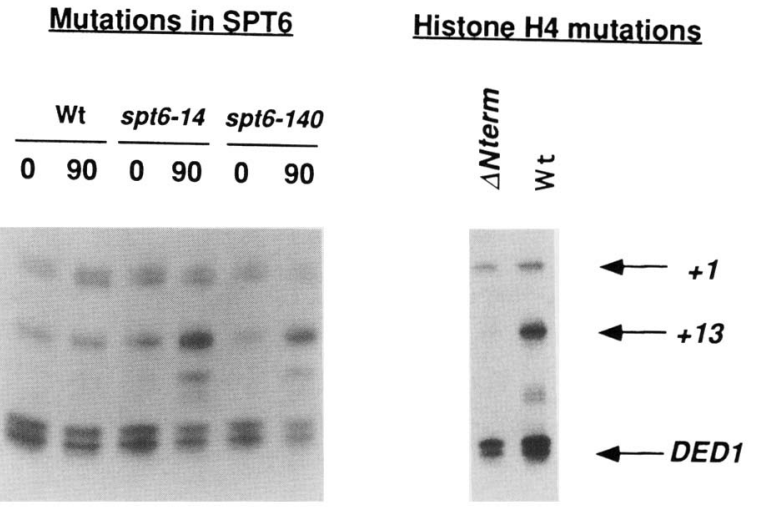

Figure 8. SPT6 and the amino-terminal tail of histone $\mathrm{H} 4$ are not involved in NOT-mediated repression. gcn4-deleted strains containing SPT6 (KY803), spt6-14 (MY433), and spt6-140 (MY432) analyzed 0 and $90 \mathrm{~min}$ after a shift to $37^{\circ} \mathrm{C}$, or GCN4 containing strains that do (PKY501) or do not (PKY813) contain the amino-terminal tail of histone $\mathrm{H} 4$ were analyzed for HIS3 $(+1$ and +13 transcripts) and DED1 RNAs.

\section{Discussion}

The NOT proteins are global negative regulators

The basic observation that recessive, presumably loss-offunction not mutations cause increased transcription formally defines the NOT proteins as negative regulators. The NOT proteins inhibit the expression of genes that carry out diverse biological functions (histidine biosynthesis, pheromone response, nuclear fusion, RNA polymerase II transcription|. However, the NOT proteins are unlikely to encode basic components of the RNA polymerase II transcription machinery because several genes $(D E D 1, O R F, T F I I B, T F I I A)$ are unaffected in not mutant strains and because null alleles of NOT2, NOT3, and NOT4 are viable.

Results presented here and elsewhere strongly support a direct role of the NOT proteins in inhibiting transcription. First, it is very unlikely that the NOT proteins inhibit transcription indirectly by activating a repressor. Increased $\mathrm{T}_{C}$-dependent transcription is observed within 30 min of shifting a not1-2 strain to the restrictive temperature (Collart and Struhl 1993), and similar results are obtained in not1-1 and not2-1 strains (data not shown). The rapid induction with loss of NOT function strongly supports a direct transcriptional effect of the NOT proteins, and it indicates that a putative repressor activated by the NOT proteins would have to be highly unstable. However, the possibility of a highly unstable repressor is inconsistent with the observation that HIS3 transcription is not affected for several hours after treatment with cycloheximide (Cormack and Struhl 1992). Finally, transcriptional analysis of nine genes provides no evidence for positive regulation by the NOT proteins.

Second, it is also unlikely that the NOT proteins exert their affects indirectly by affecting differentially the expression of the basic transcription factors that are required for initiation by RNA polymerase II. The genes 
encoding TFIIB and the small subunit of TFIIA are unaffected in not mutant strains (Fig. 1D), and overexpression of TBP or TFIIB does not confer the transcriptional initiation pattern (Fig. 1E) or the AT-resistance phenotype characteristic of not mutant strains. Furthermore, the HIS3 initiation pattern is not altered in numerous TBP mutant strains that show a general increase in RNA polymerase II transcription because they are defective in RNA polymerase III transcription (Cormack and Struhl 1993). Conversely, reduced levels of TBP (obtained by blocking transcription of the TBP gene/ do not affect the relative levels of the +1 and +13 transcripts /Cormack and Struhl 1992).

\section{The NOT proteins are related functionally}

The not mutant strains arose from the same genetic selection and have additional phenotypic similarities. Most important, mutations in all four NOT genes increase HIS3 expression in the absence of GCN4 and preferentially affect $T_{C}$-dependent transcription. Preferential effects on $\mathrm{T}_{\mathrm{C}}$-dependent transcription are unique to NOT proteins, having never been observed in numerous other situations involving the HIS3 promoter region described here and elsewhere. The not mutations also affect the same spectra of genes; transcription of HIS4, $T B P, S T E 4$, and $B I K 1$ is increased, but transcription of $D E D 1, O R F, T F I I B$, and TFIIA is not. Finally, the original not1(cdc39) and not2(cdc36) mutations have other common phenotypes including cell-cycle arrest in $\mathrm{G}_{1}$, pachytene arrest in meiosis, and inappropriate activation of the mating pheromone response (Reed 1980; Shuster and Byers 1989; de Barros Lopes et al. 1990); not4(ssf1) also activates the pheromone response pathway $\{\mathrm{K}$. Irie and $\mathrm{K}$. Matsumoto, pers. comm.). These striking similarities of the various not mutant strains strongly suggests that the four NOT proteins regulate transcription negatively through the same pathway.

Aside from these phenotypic similarities, functional relationships among the NOT proteins are inferred from a variety of genetic observations. First, not 1-2 and not2-4 are allele-specific suppressors. Second, not 2 not 3 double mutant strains grow much more poorly than either of the corresponding single mutant strains. Third, NOT3 is a high-copy and allele-specific suppressor of not1-1. Fourth, NOT4 is a high-copy suppressor of not 1 and not 2 mutations. These observations do not reflect transcriptional cross-regulation because NOT1-4 RNA levels are not affected by mutations in any of the four NOT genes (not shown). The functional relationships reinforce the conclusion that the NOT proteins act together in regulating transcription negatively.

\section{Evidence for a NOT complex}

Genetic and biochemical experiments demonstrate that NOT1 and NOT2 are components of a large, multiprotein complex. NOT1 and NOT2 are nuclear proteins and they cofractionate biochemically as a discrete $500-\mathrm{kD}$ species. This complex is relatively resistant to ionic strength and detergent, is separable from bulk protein in the extract, and is unlikely to contain DNA. The existence of a complex containing NOT1 and NOT2 is confirmed by the two-hybrid assay. From these results, it cannot be determined whether NOT1 and NOT2 interact directly with each other or with other proteins in the complex. However, the allele-specific suppression between the not 1-1 and not2-4 mutations argues in favor of a direct NOT1-NOT2 interaction.

Our results suggest, but do not prove, that NOT3 and NOT4 are also part of the complex. The strongest evidence is that NOT4 interacts with NOT1 and NOT3 in the two-hybrid assay (Table 2); NOT1 and NOT3 may also interact weakly in this assay. Supporting evidence comes from the observations that overexpression of NOT3 or NOT4 suppresses the temperature-sensitive phenotypes of not 1 and not 2 mutations (Table 1). The degree of suppression depends on the gene that is overexpressed and on the mutant allele; in at least one case (high-copy NOT3 and not1-2), suppression is not observed. Interestingly, not1-2 maps between residues 371 and 1318 (M. Collart and K. Struhl, unpubl.), whereas not1-1 is a tryptophan to arginine change of codon 1753 (Y.-K. Hong and E.O. Schuster, pers. comm.). A complex containing one molecule of each of the four NOT proteins would have a predicted molecular mass of $430 \mathrm{kD}$, a size consistent with that of the biochemically detected complex containing NOT1 and NOT2. However, we cannot exclude the possibility of multiple complexes that contain different subsets of NOT land perhaps other) proteins.

\section{NOT proteins define a novel transcriptional regulatory pathway}

Our results suggest strongly that the NOT proteins function by a mechanism that is distinct from all previously described examples of repression in yeast. NOT-mediated repression is not attributable to inhibition of activator proteins because loss of NOT function increases $\mathrm{T}_{\mathrm{C}}$-dependent transcription preferentially, whereas activator proteins function almost exclusively through $T_{R}$. Consistent with this view, not mutations increase basal HIS3 transcription, which occurs in the absence of known activator proteins. In not $2-4$ and not3-2 strains, the level of +1 transcription is actually reduced in the presence of gcn4-C163, suggesting that increased transcription upon loss of NOT function can compete with GCN4 activation. This competition is unlikely to simply reflect the proximity of the GCN4-binding site and $\mathrm{T}_{\mathrm{C}}$. Competition is not observed in most not strains, and GCN4 can activate transcription when $T_{R}$ is located at the position normally occupied by $T_{C}$ (Harbury and Struhl 1989). Thus, NOT-mediated repression and transcriptional activation are likely to occur by distinct pathways.

Repression by the CYC8/TUP1 complex and by SIN3 has been proposed to occur by their association with specific DNA-binding proteins that interact with subsets of promoters (Keleher et al. 1992; Wang and Stillman 1993; 
D. Tzamarias and K. Struhl, in prep/. This hypothesis is based primarily on the observations that CYC8, TUP1, and SIN3 can repress transcription when bound upstream of the CYC1 promoter by a heterologous DNAbinding domain. In contrast to these negative regulators, NOT1 and NOT2 are unable to repress transcription in this assay. Moreover, basal HIS3 transcription is unaffected in $c y c 8$ and tup1 deletion strains indicating that NOT-mediated repression does not require either CYC8 or TUP1. These results suggest that the NOT proteins do not regulate transcription negatively by associating with promoter-specific, DNA-binding proteins. Consistent with this view, NOT1 regulates transcription negatively from a minimal HIS3 promoter derivative containing $\mathrm{T}_{\mathrm{C}}$ and $T_{R}$ but lacking all upstream sequences /Collart and Struhl 1993).

Negative regulation by the NOT proteins also appears to be mechanistically distinct from global repression mediated through chromatin. As discussed previously /Collart and Struhl 1993), nucleosome loss in vivo leads to increased HIS 3 transcription that is entirely mediated by $T_{R}$ (Durrin et al. 1992). Similarly, loss of SPT6 function leads to a GCN4-independent increase in the level of +13 transcript. SPT6 is a negative regulatory protein that functions together with SPT4 and SPT5, possibly by affecting chromatin structure because spt mutant strains are phenotypically similar to strains lacking one of the two histone $\mathrm{H} 2 \mathrm{~A}-\mathrm{H} 2 \mathrm{~B}$ gene pairs (Swanson and Winston 1992). Finally, a histone H4 derivative lacking the amino-terminal tail, which is defective in activation and silencing of various genes (Kayne et al. 1988; Durrin et al. 1991), leads to a nearly complete loss of +13 transcription. In all of these situations, the level of the +1 transcript is unaffected, suggesting that $T_{C}$-dependent transcription is not controlled by the state of chromatin structure. Thus, it seems unlikely that the NOT proteins are involved in maintaining the normal repressive chromatin structure, although more complex effects on chromatin cannot be excluded.

\section{NOT proteins may affect the RNA polymerase II transcription machinery}

We suggest that the NOT proteins inhibit a basic transcription factor, thereby making it limiting for initiation. The TBP is an attractive candidate because the NOT proteins distinguish between $T_{C}$ and $T_{R}$, which differ with respect to TBP binding and TBP-dependent transcription in vitro (Ponticelli and Struhl 1990) yet require TBP for transcription in vivo (Cormack and Struhl 1992). Competition between NOT-mediated inhibition of TBP and specific binding of TBP to the TATA element might explain why $T_{C}$, a nonconsensus and poor binding site (Mahadevan and Struhl 1990; Ponticelli and Struhl 1990 ), is affected more strongly than $T_{R}$, a consensus and efficient binding site /Chen and Struhl 1988; Wobbe and Struhl 1990). Alternatively, the NOT proteins might act through TBP-associated proteins that are part of the yeast TFIID complex (Thompson et al. 1993) or through TFIIA, which interacts with TBP and affects TATA-ele- ment binding (Buratowski and Zhou 1992; Lee et al. 1992). Biochemical activities that inhibit TFIID function in vitro have been described (Meisterernst and Roeder 1991; Meisterernst et al. 1991; Inostroza et al. 1992; Auble and Hahn 1993), but their biological roles are unknown.

Although differential gene regulation is largely the result of the individual and combinatorial properties of specific DNA-binding activators and repressors, functional distinctions between TATA elements also play a role (Struhl 1986; Homa et al. 1988; Simon et al. 1988; Harbury and Struhl 1989; Wefald et al. 1990). In yeast, where unrelated genes are often closely packed, functionally distinct TATA elements are likely to be important for independently regulating genes that are transcribed divergently and share upstream promoter elements; such a situation occurs in the HIS3-PET56 promoter region (Struhl 1986). Thus, negative regulation by the NOT complex might represent part of the mechanism by which yeast cells distinguish functionally among TATA elements at various promoters.

\section{Materials and methods}

\section{Yeast strains}

The yeast strains used in this work are listed in Table 4 and were generated by standard genetic techniques. The not mutations were isolated from strains KY1600 (Collart and Struhl 1993) and KY1601, derivatives of KY803 (Hope and Struhl 1986) and KY804 that contain YCp88-Sc4363, a URA3 centromeric vector that expresses gen4-C163 from the $D E D 1$ promoter, and YCp87-Sc3866, a LEU2 centromeric vector containing a his3lacZ fusion under the control of a promoter with an optimal AP-1 site upstream of the HIS3 TATA region. KY804 is an isogenic $\alpha$ derivative of KY803, which was obtained by $\mathrm{HO}$-mediated mating-type switching (Herskowitz and Jensen 1991). The not mutant strains were generated as spontaneous revertants that grew on glucose minimal plates containing $20 \mathrm{mM}$ AT and were blue on X-gal indicator plates (Collart and Struhl 1993). To analyze basal HIS3 transcription in the not strains, both plasmids were cured. Disruption of the HIS3 locus was performed by one-step gene replacement with Sc3445, which carries the his3::TRP1 allele (Struhl 1987). To eliminate TUP1 and CYC8 function, tup $1:: L E U 2$ (lacks TUP1 codons 70-262) and cyc8::LEU2 (lacks CYC8 codons 99-862) substitution alleles were introduced into KY803 by one-step gene replacement. Isogenic derivatives of KY803 carrying the spt6-140, spt6-14, and not 1-1 alleles were generated by two successive gene replacement events with pAB56 and pAB75 DNAs lobtained from A. Bortvin, Harvard Medical School) or with YIp5-not1-1 DNA (obtained from Y.-K. Hong and E.O. Schuster). The not3::URA3 and not $4:: U R A 3$ derivatives of KY803 were obtained by onestep gene replacement with Sc3877 and Sc3883.

\section{DNA manipulations}

NOT2 was cloned by complementation of the not2-1 mutation. A YCp50 library containing partial Sau3A fragments of yeast genomic DNA (obtained from M. Rose, Princeton University, NJ) was introduced into MY27 and selected for growth at $37^{\circ} \mathrm{C}$. Four plasmids containing 15-20 kb of yeast DNA were recovered from such transformants and shown to complement both phenotypes. The following fragments were subcloned into 
Table 4. Strain list

\begin{tabular}{|c|c|c|}
\hline Strain & Genotype & Source \\
\hline KY803 & a ura3-52 trp1- $\Delta 1$ leu2::PET56 gal2 gcn4- 1 & Hope and Struhl (1986) \\
\hline KY804 & isogenic to KY803 except $\alpha$ & this work \\
\hline KY1600 & KY803 (YCp88-gcn4-C163 + YCp87-Sc3866) & Collart and Struhl (1993) \\
\hline KY1601 & isogenic to KY1600 except $\alpha$ & this work \\
\hline MY28 & KY804 not1-2 & Collart and Struhl (1993) \\
\hline MY27 & KY803 not2-1 & this work \\
\hline MY22 & KY803 not2-4 & this work \\
\hline MY25 & KY803 not3-2 & this work \\
\hline MY21 & KY803 not3-4 & this work \\
\hline MY18 & KY803 not3-5 & this work \\
\hline MY20 & KY803 not4-1 & this work \\
\hline MY508 & KY803 not $3:: U R A 3$ & this work \\
\hline MY509 & KY803 not1-1 & this work \\
\hline MY520 & KY803 not4::URA3 & this work \\
\hline MY146 & KY803 not2-1 not $3-5$ & this work \\
\hline MY42 & KY803 not $1-2$ not2-1 & this work \\
\hline MY210 & KY803 not1-2 not2-4 & this work \\
\hline MY340 & MY804 not1-2 (bc9b-HA1-NOT1) & this work \\
\hline MY55 & KY804 not1-2 his3::TRP1 & Collart and Struhl (1993) \\
\hline MY66 & KY803 not3-2 his3::TRP1 & this work \\
\hline MY32 & KY803 not4-1 his3::TRP1 & this work \\
\hline ELY54 & a not1-1 ace6 his 4 lys2 trp1 & Steve Reed (pers. comm.) \\
\hline EGY42 & a trp1 ura3 his3 LEU2::plexAop6-LEU2 & Zervos et al. (1993) \\
\hline MY94 & a ade1 his2 leu2 trp1 ura3 not2::TRP1 & Steve Reed \\
\hline MY96 & KY804 $\Delta c y c 8:: L E U 2$ & this work \\
\hline MY97 & KY804 $\Delta$ tup $1:: L E U 2$ & this work \\
\hline MY276 & a his3- $\Delta 200$ ura3-52 trp1- $\Delta 63$ ura3::CYC-lacZ & D. Tzamarias and K. Struhl \\
\hline MY277 & isogenic to MY276 except ura3::lexAop-CYC-1acZ & D. Tzamarias and K. Struhl \\
\hline MY432 & KY803 spt6-140 & this work \\
\hline MY433 & KY803 stp6-14 & this work \\
\hline PKY501 & $\begin{array}{l}\text { a ade2-101 arg4-1 his3- } \Delta 200 \text { leu2-3, } 112 \text { lys2-801 } \\
\text { trp1- } 1 \text { 1ura3-52 thr tyr } \Delta \text { hhf1::HIS3 } \Delta \text { hhf2::LEU2 } \\
\text { (pURA3 CEN3 ARS1 HHF2) }\end{array}$ & Kayne et al. (1988) \\
\hline PKY813 & PKY501 except (pURA3 CEN3 ARS1 hhf2- $\Delta 4-28$ ) & Kayne et al. (1988) \\
\hline
\end{tabular}

pRS306 or pRS316 (Sikorski and Hieter 1989): Sc3867, 3-kb EcoRI fragment present in all four clones; Sc3868, an adjacent EcoRI-BgIII fragment; Sc3869, an internal NdeI deletion of Sc3867; Sc3870, a SacI-PstI fragment of Sc3867. For overexpression, Sc3870 was cloned into YEplac195 (Gietz and Sugino 1988). For two-hybrid assays, NOT2 protein-coding sequences from the initiation codon were obtained by PCR amplification of Sc3870 with GCCGAATTCATGGAAAAATTTGGTTTAAAAGCGCTAGTACCGC and GCCGTCGACCTGCAGACCTTTCCCTATCGCC, digested by EcoRI and SalI, and ligated into Lex202 and pJG4-5 (Zervos et al. 1993).

NOT3 was cloned by complementation of the not3-5 allele by introducing the library described above into MY146 and selecting transformants that grew better than untransformed cells at $25^{\circ} \mathrm{C}$ but did not grow at $37^{\circ} \mathrm{C}$. A single plasmid containing 15 $\mathrm{kb}$ of yeast DNA ( $\mathrm{Sc3876}$ ) was recovered and shown to complement the growth and AT-resistance phenotypes. YCp50 derivatives containing Sc3871, Sc3872, and Sc3874 were obtained by digesting YCp50-Sc3876 with EagI, SacI, and ClaI, respectively, and religating the largest fragments. Sc3873, a ClaI-SacI fragment of Sc3874, was partially sequenced. For two-hybrid assays, NOT3 protein-coding sequences from the initiation codon were obtained by cloning the SacI-Sall fragment obtained by PCR amplification of Sc3874 with GCCGTCGACAGTTTATGCCCATTCGCTATTCAACATGTTTGGTGG and CGGGAGCT-
CCTCACATCATCCTTTAGTTTCCTTGGCGACAAATCC, and an EcoRI-SacI fragment generated by PCR amplification of Sc3873 using the forward primer and GCCGAATTCATGGCTCATAGAAAATTACAGCAGGAGGTCGATAGGG, into Lex202 and pJG4-5 (Zervos et al. 1993). For NOT3 overexpression, the ClaI-SacI fragment of Sc3873 and the SacI-NdeI fragment of Sc3875 were cloned into SalI-BamHI-digested YEplac1 12 (Gietz and Sugino 1988).

To generate LexA-NOT1 and B42-NOT1, NOT1 sequences were PCR amplified from Sc3863 (Collart and Struhl 1993) with GCCGAATTCATGCTATCGGCCACATACCGTGATTTGAACACAGC and GTTGAGCTCTTATTTGTTCGGAGGTTAGGATTTGGGTAGGC, and digested with EcoRI and SacI. This fragment was combined with SacI-BglII-cleaved Sc3861 (Collart and Struhl 1993) and then cloned into Lex202 and pJG4-5 digested with EcoRI and BamHI (Zervos et al. 1993). cyc8::LEU2 was generated by cloning the XhoI-SalI LEU2 fragment between the PstI sites within the CYC8 gene. tup $1:: L E U 2$ was generated by cloning the same LEU2 fragment between the EcoRI and BamHI sites in TUP1.

NOT4 was cloned by complementation of the not4-1 mutation by introducing the library described above into MY20 and selecting transformants that grew better than untransformed cells. Two plasmids containing $10 \mathrm{~kb}$ of yeast DNA were recovered and shown to complement the AT-resistant phenotype. 
pRS316-Sc3878 was obtained by cloning a 6.3-kb HindIII-EagI fragment from the initial clones containing a 6-kb HindIIIEcoRI fragment of genomic DNA into pRS316. Partial sequencing around the SmaI, BamHI, and EcoRI sites revealed that this gene was identical to $S S F 1$, a gene isolated by $\mathrm{K}$. Irie and $\mathrm{K}$. Matsumoto. For overexpression of NOT4, the 6-kb HindIIIEcoRI fragment of Sc3878 was cloned into YEplac112 and YEPlacl81. For two-hybrid assays, NOT4 protein-coding sequences from the initiation codon were amplified by PCR amplification of Sc3878 with GCCCGTCGACCAACCAACTGCGCAAGAGATTTCGTTG and GCCGAATTCATGATGAATCCACACGTTCAAGAAAATTTGC, digested by EcoRI and Sall and cloned into Lex202 and pJG4-5.

\section{RNA analysis}

Total RNA $(30 \mu \mathrm{g})$ from cells grown under appropriate conditions were hybridized to completion with an excess $(2 \mathrm{ng})$ of the appropriate oligonucleotides, and the products were digested with S1 nuclease and electrophoretically separated as described previously (Collart and Struhl 1993). All hybridization reactions contained multiple probes to ensure that the determinations were controlled internally. Northern blots were performed as described previously (Collart and Struhl 1993) using the following probes: a 6-kb HindIII fragment containing BIK1 and $O R F$ (Trueheart et al. 1987); a TFIIA fragment obtained by PCR amplification of genomic DNA with GATCGAATTCCATGAACTGAATTGTCAATAC and GAAGGATTCCATTATTTCATGACACTGTTCC; artificially generated NdeI-BamHI and EcoRI-SalI restriction fragments containing the entire $T B P$ - and TFIIB-coding sequences; an 11-kb BamHI-SphI fragment from EB125 (Collart and Struhl 1993) for STE4.

\section{Subcellular localization or NOT2}

Total cellular, nuclear, and cytoplasmic extracts were prepared as described previously (Collart and Struhl 1993). Total protein from each extract $50 \mu \mathrm{g}$ as quantitated by the Bio-Rad/Bradford assay) was separated on a $12 \%$ SDS-polyacrylamide gel, and electroblotted on to polyvinylidene difluoride membranes. NOT2 was detected with a polyclonal antibody $(7412$ kindly supplied by S. Reed) used at a 1:500 dilution, followed by a 1:5000 dilution of goat anti-rabbit IgG-specific antibody conjugated to alkaline phosphatase.

\section{$\beta$-Galactosidase assays}

For two-hybrid assays, stationary cells were diluted 50 -fold in minimal medium containing $2 \%$ raffinose, grown for $12 \mathrm{hr}$, washed twice, and grown 4-5 hr in minimal medium containing $4 \%$ galactose. For experiments not involving galactose induction, cells were grown to log phase in glucose minimal medium. For experiments testing repression, cells were grown from inoculation of a single colony to an $\mathrm{OD}<1$. In all cases, cells were spun down and lysed with glass beads in $0.1 \mathrm{M}$ Tris $(\mathrm{pH} 8), 20 \%$ glycerol, $1 \mathrm{~mm}$ DTT and $2 \mathrm{mM}$ PMSF; $\beta$-galactosidase activities were normalized to protein concentration.

\section{Gel filtration}

Cells (100 ml) were grown overnight in glucose medium containing casamino acids to late log phase and washed once in buffer [ $40 \mathrm{~mm}$ HEPES (pH 7.2), $5 \%$ glycerol, $350 \mathrm{~mm} \mathrm{NaCl}, 0.1 \%$ Tween, and protease inhibitors]. The cell pellet was resuspended in buffer at $100-200 \mathrm{OD} / \mathrm{ml}(2.5 \mathrm{ml})$ and glass beads were added. Cells were broken by vortexing four times for 20 $\mathrm{sec}$, and the extract was clarified by centrifugation at $100,000 \mathrm{~g}$ for $1 \mathrm{hr}$. The supernatant was filtered through $0.45-\mu \mathrm{m}$ pores, and $250 \mu \mathrm{l}$ of the extract was loaded on a fast protein liquid chromotography Superose 6 column. The column was washed with buffer, and $250 \mu \mathrm{l}$ fractions were collected. Proteins from these fractions were precipitated with TCA and analyzed by Western blotting using rabbit polyclonal antibodies to NOT2 (7412 from S. Reed), or the HAl-specific monoclonal antibody that recognizes epitope-tagged NOT1 (Collart and Struhl 1993). A mixture of five proteins $10.5 \mathrm{mg} / \mathrm{ml}$ of blue dextran, $1 \mathrm{mg} / \mathrm{ml}$ of human $\mathrm{IgG}, 1 \mathrm{mg} / \mathrm{ml}$ of BSA, $1 \mathrm{mg} / \mathrm{ml}$ of cytochrome $c$, and $4 \mathrm{mg} / \mathrm{ml}$ of aprotinin) was analyzed under the same conditions to determine the elution volumes of proteins with known molecular weights. To determine the extent of DNA contamination, $125 \mu \mathrm{l}$ of total cell extract, with or without RNase A treatment, was analyzed by agarose gel electrophoresis; DNA was not detected.

\section{Acknowledgments}

We thank David Chan for help in the cloning and initial characterization of NOT2, Lynn Mendelman for her expert advice and assistance in carrying out the FPLC experiments, Steve Reed, Elisabeth Shuster, and Kunihiro Matsumoto for communicating unpublished information, Linda Riles for supplying the genomic mapping filters and interpreting the hybridization results, Steven Reed for antibodies, Alexei Bortvin, Roger Brent, Elaine Elion, Michael Grunstein, Y.-K. Hong, Vijak Mohdavi, Steven Reed, Elisabeth Shuster, and Dimitris Tzamarias for yeast strains and DNAs, and Fred Winston for fruitful discussions during the course of the experiments. This work was supported by a postdoctoral fellowship to M.A.C. from the Swiss National Fund and by grant GM30186 to K.S. from the National Institutes of Health.

The publication costs of this article were defrayed in part by payment of page charges. This article must therefore be hereby marked "advertisement" in accordance with 18 USC section 1734 solely to indicate this fact.

\section{Note added in proof}

We recently found that the NOT4 sequence has been described previously as $S I G 1$, a gene involved in G-protein-mediated pheromone response (E. Leberer, D. Dignard, D. Harcus, M. Whiteway, and D.Y. Thomas, unpubl.; accession number M96736).

\section{References}

Auble, D.T. and S. Hahn. 1993. An ATP-dependent inhibitor of TBP binding to DNA. Genes \& Dev. 7: 844-856.

Buratowski, S. and H. Zhou. 1992. Transcription factor IID mutants defective for interaction with transcription factor IIA. Science 255: 1130-1132.

Chen, W. and K. Struhl. 1988. Saturation mutagenesis of a yeast his3 TATA element: Genetic evidence for a specific TATAbinding protein. Proc. Natl. Acad. Sci. 85: 2691-2695.

Collart, M.A. and K. Struhl. 1993. CDC39, an essential nuclear protein that negatively regulates transcription and differentially affects the constitutive and inducible his 3 promoters. EMBO I. 12: 177-186.

Cormack, B.P. and K. Struhl. 1992. The TATA-binding protein is required for transcription by all three nuclear RNA polymerases in yeast cells. Cell 69: 685-696.

1993. Regional codon randomization: Defining a TATAbinding protein surface required for RNA polymerase III transcription. Science 262: 244-248.

de Barros Lopes, M., J.-Y. Ho, and S.I. Reed. 1990. Mutations in 
cell division cycle genes $C D C 36$ and $C D C 39$ activate Saccharomyces cerevisiae mating pheromone response pathway. Mol. Cell. Biol. 10: 2966-2972.

Durrin, L.K., R.K. Mann, P.S. Kayne, and M. Grunstein. 1991. Yeast histone $\mathrm{H} 4 \mathrm{~N}$-terminal sequence is required for promoter activation in vivo. Cell 65: 1023-1031.

Durrin, L.K., R.K. Mann, and M. Grunstein. 1992. Nucleosome loss activates CUP1 and HIS3 promoters to fully induced levels in the yeast Saccharomyces cerevisiae. Mol. Cell. Biol. 12: 1621-1629.

Ferguson, J., J.-Y. Ho, T.A. Peterson, and S.I. Reed. 1986. Nucleotide sequence of the yeast cell division cycle start genes $C D C 28, C D C 36, C D C 37$, and $C D C 39$, and a structural analysis of the predicted proteins. Nucleic Acids Res. 14: 66816697.

Fields, S. and O.-K. Song. 1989. A novel genetic system to detect protein-protein interactions. Nature 340: 245-246.

Gietz, R.D. and A. Sugino. 1988. New yeast-Escherichia coli shuttle vectors constructed with in vitro mutagenized yeast genes lacking six-base pair restriction sites. Gene 74: 527-534.

Harbury, P.A.B. and K. Struhl. 1989. Functional distinctions between yeast TATA elements. Mol. Cell. Biol. 9: 5298-5304.

Herskowitz, I. and R.E. Jensen. 1991. Putting the HO gene to work: Practical uses for mating-type switching. Methods Enzymol. 194: 132-146.

Hirschhorn, J.N., S.A. Brown, C.D. Clark, and F. Winston. 1992. Evidence that SNF2/SWI2 and SNF5 activate transcription in yeast by altering chromatin structure. Genes \& Dev. 6: 2288-2298.

Homa, F.L., J.C. Gloriosom, and M. Levine. 1988. A specific 15-bp TATA box promoter element is required for expression of a herpes simplex virus type I late gene. Genes \& Dev. 2: $40-53$.

Hope, I.A. and K. Struhl. 1986. Functional dissection of a eukaryotic transcriptional activator protein, GCN4 of yeast. Cell 46: 885-894.

Inostroza, J.A., F.H. Mermelstein, I. Ha, W.S. Lane, and D. Reinberg. 1992. Dr1, a TATA-binding protein-associated phosphoprotein and inhibitor of class II gene transcription. Cell 70: $477-489$.

Kayne, P.S., U.-J. Kim, M. Han, J.R. Mullen, F. Yoshizaki, and M. Grunstein. 1988. Extremely conserved histone H4 N-terminus is dispensible for growth but essential for repressing the silent mating loci in yeast. Cell 55: 27-39.

Keleher, C.A., M.J. Redd, J. Schultz, M. Carlson, and A.D. Johnson. 1992. Ssn6-Tupl is a general repressor of transcription in yeast. Cell 68: 709-719.

Laurent, B.C. and M. Carlson. 1992. Yeast SNF2/SWI2, SNF5, and SNF6 proteins function coordinately with the gene-specific transcriptional activators GAL4 and Bicoid. Genes \& Dev. 6: 1707-1715.

Laurent, B.C., M.A. Treitel, and M. Carlson. 1991. Functional interdependence of the yeast SNF2, SNF5, and SNF6 proteins in transcriptional activation. Proc. Natl. Acad. Sci. 88: $2687-2691$.

Lee, D.K., J. Dejong, S. Hashimoto, M. Horikoshi, and R.G. Roeder. 1992. TFIIA induces conformational changes in TFIID via interactions with the basic repeat. Mol. Cell. Biol. 12: 5189-5196.

Mahadevan, S. and K. Struhl. 1990. $\mathrm{T}_{\mathrm{C}}$, an unusual promoter element required for constitutive transcription of the yeast his3 gene. Mol. Cell. Biol. 10: 4447-4455.

Meisterernst, M. and R.G. Roeder. 1991. Family of proteins that interact with TFIID and regulate promoter activity. Cell 67: 557-567.

Meisterernst, M., A.L. Roy, H.M. Lieu, and R.G. Roeder. 1991.
Activation of class II gene transcription by regulatory factors is potentiated by a novel activity. Cell 66: 981-993.

Olson, M.V., J.E. Dutchik, M.Y. Graham, G.M. Brodeur, C. Helms, M. Frank, M. Maccollin, R. Scheinman, and T. Frank. 1986. Random-clone strategy for genomic restriction mapping in yeast. Proc. Natl. Acad. Sci. 83: 2444-2448.

Peterson, C.L. and I. Herskowitz. 1992. Characterization of the yeast $S W I 1, S W I 2$, and $S W I 3$ genes, which encode a global activator of transcription. Cell 68: 573-583.

Ponticelli, A.S. and K. Struhl. 1990. Analysis of Saccharomyces cerevisiae his3 transcription in vitro: Biochemical support for multiple mechanisms of transcription. Mol. Cell. Biol. 10: $2832-2839$.

Reed, S.I. 1980. The selection of $S$. cerevisiae mutants defective in the start event of cell division. Genetics 95: 561-577.

Shuster, E.O. and B. Byers. 1989: Pachytene arrest and other meiotic effects of start mutations in Saccharomyces cerevisiae. Genetics 123: 29-43.

Sikorski, R.S. and P. Hieter. 1989. A system of shuttle vectors and yeast host strains designed for efficient manipulation of DNA in Saccharomyces cerevisiae. Genetics 122: 19-27.

Simon, M.C., T.M. Fisch, B.J. Benecke, J.R. Nevins, and N. Heintz. 1988. Definition of multiple, functionally distinct TATA elements, one of which is a target in the $h s p 70$ promoter for E1A regulation. Cell 52: 723-729.

Struhl, K. 1986. Constitutive and inducible Saccharomyces cerevisiae promoters: Evidence for two distinct molecular mechanisms. Mol. Cell. Biol. 6: 3847-3853.

- 1987. The DNA-binding domains of the jun oncoprotein and the yeast GCN4 transcriptional activator are functionally homologous. Cell 50: 841-846.

- 1993. Yeast transcription factors. Curr. Opin. Cell Biol. 5: 513-520.

Swanson, M.S. and F. Winston. 1992. SPT4, SPT5, and SPT6 interactions: Effects on transcription and viability in Saccharomyces cerevisiae. Genetics 132: 325-336.

Thompson, C.M., A.J. Koleske, D.M. Chao, and R.A. Young. 1993. A multisubunit complex associated with the RNA polymerase II CTD and TATA-binding protein in yeast. Cell 73: 1361-1375.

Trueheart, J., J.D. Boeke, and G.R. Fink. 1987. Two genes required for cell fusion during yeast conjugation: Evidence for a pheromone-induced surface protein. Mol. Cell. Biol. 7: 2316-2328.

Wang, H. and D.J. Stillman. 1993. Transcriptional repression in Saccharomyces cerevisiae by a SIN3-LexA fusion protein. Mol. Cell. Biol. 13: 1805-1814.

Wefald, F.C., B.H. Devlin, and R.S. Williams. 1990. Functional heterogeneity of mammalian TATA-box sequences revealed by interaction with a cell-specific enhancer. Nature 344: 260-262.

Williams, F.E., U. Varanasi, and R.J. Trumbly. 1991. The CYC8 and TUP1 proteins involved in glucose repression in Saccharomyces cerevisiae are associated in a protein complex. Mol. Cell. Biol. 11: 3307-3316.

Wobbe, C.R. and K. Struhl. 1990. Yeast and human TATA-binding proteins have nearly identical DNA sequence requirements for transcription in vitro. Mol. Cell. Biol. 10: 38593867.

Yoshinaga, S.K., C.L. Peterson, I. Herskowitz, and K.R. Yamamoto. 1992. Roles of SWI1, SWI2, and SWI3 proteins for transcriptional enhancement by steroid receptors. Science 258: 1598-1604.

Zervos, A.S., J. Gyuris, and R. Brent. 1993. Mxil, a protein that specifically interacts with Max to bind Myc-Max recognition sites. Cell 72: 223-232. 


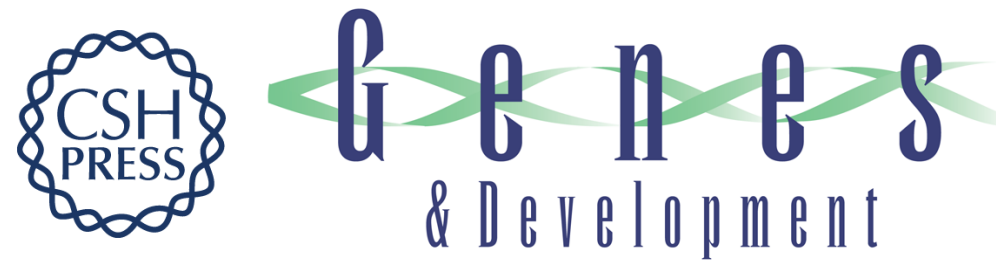

\section{NOT1(CDC39), NOT2(CDC36), NOT3, and NOT4 encode a global-negative regulator of transcription that differentially affects TATA-element utilization.}

M A Collart and K Struhl

Genes Dev. 1994, 8:

Access the most recent version at doi:10.1101/gad.8.5.525

References This article cites 45 articles, 24 of which can be accessed free at: http://genesdev.cshlp.org/content/8/5/525.full.html\#ref-list-1

License

Email Alerting Service

Receive free email alerts when new articles cite this article - sign up in the box at the top right corner of the article or click here.

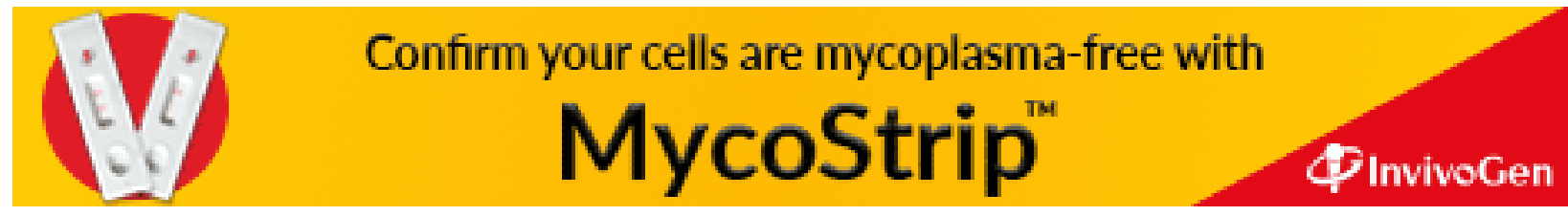

